Friendships and social acceptance of children with disabilities: The role of classroom quality, individual skills, and ECEC dosage

Milene Ferreira $^{1}$, Cecília Aguiar ${ }^{2}$, Nadine Correia $^{2}$, Margarida Fialho $^{2}$, and Júlia Serpa Pimentel $^{1}$

${ }^{1}$ ISPA- Instituto Universitário, Lisbon, Portugal

${ }^{2}$ Instituto Universitário de Lisboa (ISCTE-IUL), CIS-IUL, Lisbon, Portugal

Author Note

This work was funded by Portuguese National Funds, via FCT — Fundação para a Ciência e a Tecnologia, through research grant PTDC/CPE-CED/117476/2010, and is a partial fulfillment of the requirements for the degree of Doctor in Psychology by the first author. 
NOTICE: this is the author's version of a work that was accepted for publication in Topics in Early Childhood Special Education. Changes resulting from the publishing process, such as peer review, editing, corrections, structural formatting, and other quality control mechanisms may not be reflected in this document. Changes may have been made to this work since it was submitted for publication. A definitive version was subsequently published as:

Ferreira, M., Aguiar, C., Correia, N., Fialho, M., \& Pimentel, J. S. (2019). Friendships and social acceptance of children with disabilities: The role of classroom quality, individual skills, and ECEC dosage. Topics in Early Childhood Special Education.

doi:10.1177/0271121419864419 


\begin{abstract}
Positive social experiences with peers are important for children with disabilities attending inclusive early childhood education (ECE). This study investigated the associations between classroom quality, children's verbal, social, and behavioral skills, and the friendships and social acceptance of children with disabilities, while testing the moderating effects of ECE dosage. Eighty-six children with disabilities ( 63 boys; $M_{\text {age }}=67.53, S D=10.54$ ), attending 86 inclusive ECE classrooms from the Metropolitan Area of Lisbon, Portugal, participated in the study. We found no effects of classroom quality on children's social acceptance and friendships and ECE dosage did not moderate this association. However, ECE dosage moderated the association between children's individual skills and their social acceptance and friendships. Findings suggest more time in ECE is not enough to support children's social acceptance, particularly for children with increased language and behavioral difficulties, who likely require more intensive and individualized interventions to support their peer-related social experiences.
\end{abstract}

Keywords: classroom quality, children with disabilities, social acceptance, friendships, dosage 


\section{Friendships and social acceptance of Portuguese children with disabilities: The role of classroom quality, individual skills, and dosage}

Social outcomes such as establishing positive relationships and developing a sense of belonging and membership are central to high-quality early childhood inclusion (DEC/NAEYC, 2009). Research suggests children with disabilities attending inclusive early childhood education (ECE) settings are positively engaged in social interaction with peers without disabilities (Tsao et al., 2008) and are more likely to have a reciprocal friendship than children attending specialized settings, probably because of greater exposure to more peers without disabilities (Buysse, Goldman, \& Skinner, 2002). However, compared to their typically developing peers, children with disabilities spend more time alone in inclusive ECE classrooms (Gamelas, 2003), experience infrequent social engagement with peers (Reszka, Odom, \& Hume, 2012), have few friends (Meyer \& Ostrosky, 2016), and are at higher risk of social rejection (Odom et al., 2006).

High-quality ECE seems to have positive and persistent effects on children's development (Burchinal et al., 2008; Buyse, Verschueren, Doumen, Damme, \& Maes, 2008; Mashburn et al., 2008). ECE quality encompasses multiple features, typically organized around two major dimensions: structural quality (i.e., regulatable dimensions such as teacher education and group size) and process quality (e.g., peer interactions, and teacher-child interactions) (Cryer, Tietze, Burchinal, Leal, \& Palacios, 1999). A considerable body of research focusing on the effectiveness of teacher-child interactions has described three major domains of process quality: emotional support, classroom organization, and instructional support (Downer, Sabol, \& Hamre, 2010; Pianta, La Paro, \& Hamre, 2008). Children who attend emotionally supportive classrooms display higher levels of social skills and lower levels of problem behaviors (Mashburn et al., 2008). Classroom processes such as behavior management and productivity are associated with children's self-regulation and school 
engagement (Rimm-Kaufman, Curby, Grimm, Nathanson \& Brock, 2009). Finally, high instructional support that fosters concept development, provides high-quality feedback, and encourages communication is associated with children's academic and social outcomes (Burchinal et al., 2008).

Importantly, Buyse et al. (2008) found positive effects of emotional support for children with internalizing and externalizing behavior. Similarly, moderating effects of emotional support were found for prosocial behaviors of children with caregivers with depressive symptoms (Johnson, Seidenfeld, Izard, \& Kobak, 2013). Furthermore, experiencing high levels of emotional support seems to improve social skills and adjusted behavior of children from families who are experiencing poverty (Burchinal, Vandergrift, Pianta, \& Mashburn, 2010). Interestingly, moderate-to-low emotional support does not predict social competence but positively predicts problem behaviors (Burchinal et al., 2010). Mikami, Griggs, Reuland, and Gregory (2012) reported low social preference stability for children attending classrooms with higher levels of emotional support, which may translate into increased opportunities for children with initial lower social preference.

Collectively, these findings support the hypothesis that classroom quality impacts peerrelated social experiences of children with disabilities in inclusive ECE settings. In the US, West (2008) found that classroom global quality was positively associated with the number of friends of children with disabilities. However, previous research focusing on the associations between classroom quality and the social acceptance of children with disabilities in Portuguese inclusive ECE settings found no evidence of such associations (e.g., Aguiar, Moiteiro, \& Pimentel, 2010). It is possible that ECE quality was not sufficient to produce the expected effects. Further, the measure of ECE quality included dimensions of structural quality unlikely to be associated with social outcomes, and children's exposure to ECE was not considered. 
Classroom processes may influence development in different ways, depending on their frequency and duration (Bronfenbrenner \& Morris, 2006), which may help explain the low to moderate effect sizes reported for ECE quality. Different approaches to measuring children's exposure to ECE, or dosage, include hours per day or per week and attendance (Xue et al., 2016; Zaslow et al., 2010). Although exposure to ECE seems to be related to children's academic outcomes (e.g., Xue et al., 2016), effects on socio-behavioral outcomes are less clear. Some studies have reported positive effects of exposure to high-quality ECE classrooms, namely for children from low-income backgrounds (Zaslow et al., 2010); however, other studies have found no effects of ECE exposure on children's social skills and problem behaviors (Xue et al., 2016). Importantly, no previous studies have focused on the role of ECE dosage on the social experiences of children with disabilities.

ECE inclusion seems to be associated with the social outcomes of children with and without disabilities (e.g., Buysse et al., 2002; Diamond, Hong, \& Tu, 2008). Specifically, the proximity afforded by ECE inclusion may increase opportunities for the development of friendships between children with different abilities (Yu, Ostrosky, \& Fowler, 2014). Friendship is based on reciprocity: friends spend time together, play, and show mutual affection, across time and in different activities (Goldman, 2007). However, simply being together is not enough to promote friendships between children with and without disabilities (Diamond et al., 2008) or to ensure social acceptance at the group level (Odom et al., 2006).

Children's disability profile may influence the extent to which they are chosen to play by their typically developing peers (Yu et al., 2014). For example, children with physical disabilities are less likely to be chosen to participate in an activity requiring motor skills by typically developing children (Diamond et al., 2008). Further, children without disabilities tend to choose to play with children with disabilities more often if they do not identify them as having disabilities (Yu et al., 2014). However, the few studies focusing on the severity of 
children's disability reported mixed findings, with Buysse et al. (2002) finding no associations with the number of friends and Aguiar et al. (2010) reporting positive associations with peer acceptance. Note that children's social and language skills have been identified as factors likely to protect children with disabilities from peer relationship difficulties (Son et al., 2014). Likewise, social skills of children with disabilities enhance their peer acceptance and friendships (Meyer \& Ostrosky, 2016). In addition, age and gender of children with disabilities also seem to influence their social experiences with peers (Aguiar et al., 2010; Diamond et al., 2008).

\section{Context and Current Study}

Our study was conducted in Portugal, adding evidence from Europe to a field that builds mostly on North American samples. Portugal has relatively high ECE coverage rates, with $77 \%, 91 \%$, and $96 \%$ of 3, 4 and 5-year-olds attending ECE (DGEEC, 2015), and has recently established the universality of preschool education for children aged four or above (DecreeLaw No. 65/2015). Enrollment rates of children with disabilities in regular ECE classrooms are also high. About $99 \%$ of all Portuguese children with disabilities have access to mainstream education (87\% in the public-school system), with most children (87\%) participating full-time in regular classrooms (DGEEC, 2016). Available evidence suggests that about $20 \%$ of regular classrooms, in the public ECE system, serve at least one child with disabilities (Inspeção-Geral de Educação e Ciência, 2015). Typically, Portuguese inclusive ECE classrooms are composed of 20 children, with a maximum of two children with disabilities. The Portuguese ECE system includes public, private for profit, and private nonprofit centers. In public and private non-profit ECE settings, the educational component (5 hours per day) is free. Relatedly, children typically attend centers five days a week, for a minimum of 5 hours per day. Importantly, previous studies have described mediocre levels of ECE quality (Aguiar et al., 2010; Cadima, Aguiar, \& Barata, 2018). 
We examined the associations between classroom quality and the social outcomes of children with disabilities, specifically number of friendships and peer social acceptance, while investigating the moderating effects of dosage. We focused on the conditions under which inclusive ECE settings facilitate positive social outcomes for children with disabilities. Based on Bronfenbrenner's model of human development (Bronfenbrenner \& Morris, 2006), we considered how the quality of selected proximal processes (i.e., teacher-child interactions) in the inclusive classroom microsystem (i.e., context) and person characteristics (i.e., individual skills) interacted with the extent of exposure (i.e., dosage) to produce optimal peer-related social outcomes, at the dyadic and the group level.

This is the first study focusing on the associations between classroom quality and the friendships and social acceptance of children with disabilities and on the role of ECE exposure on the social outcomes of children with disabilities. We expected children with disabilities attending higher-quality ECE classrooms to exhibit higher social acceptance (H1.1) and more friends (H1.2). We also expected these associations to be stronger when children missed fewer school days (H1.1a, H1.2a) and spent more months with the teacher (H1.1b, H1.2b). Further, we investigated the associations between children's individual verbal, social, and behavioral skills and their friendships and social acceptance, also assuming these associations would be moderated by ECE dosage. We hypothesized that children with more verbal and social competence, and fewer problem behaviors would be more accepted by their peers (H2.1, H3.1, and H4.1, respectively) and would have more friends (H2.2, H3.2, and H4.2, respectively). We further expected that children with less verbal, social, and behavioral skills who missed more school days or spent less time with the teacher would be less accepted by their peers (H2.1a, H3.1a, H4.1a and H2.1b, H3.1b, H4.1b, respectively) and would have fewer friends (H2.2a, H3.2a, H4.2a and H2.2b, H3.2b, H4.2b, respectively). Figure 1 presents a simplified model of the hypothesized associations among variables. In 
sum, we addressed the following research questions: Is classroom quality associated with the friendships and social acceptance of children with disabilities? Are children's individual verbal, social, and behavioral skills associated with their friendships and social acceptance? Finally, does the strength of these associations vary as a function of exposure to ECE?

\section{Method}

\section{Participants}

Participants were 86 children with disabilities (63 boys), attending 86 inclusive ECE classrooms from the Metropolitan Area of Lisbon, Portugal. Their age ranged between 45 and 88 months $(M=67.53, S D=10.54)$. Mothers' education varied considerably: $14 \%$ had a university degree, $25.6 \%$ completed high-school (i.e., 12 years of education), and the remaining had not completed high-school, with $16.3 \%$ completing 4 years of schooling or less. Information was missing for $9.3 \%$ of the mothers.

Based on teachers' report, $29 \%$ of the children had developmental delay, $22 \%$ had autism spectrum disorders, 9\% had a rare disorder (e.g., Guillian-Barré syndrome, WAGR Syndrome, Goldenhar Syndrome), 8\% had speech or language impairments, 5\% had cerebral palsy, $4 \%$ had Down syndrome, $2 \%$ had multiple disabilities, $2 \%$ had emotional disabilities, $9 \%$ had other disabilities, $6 \%$ had no diagnosis (e.g., ongoing assessment), and data were missing for $4 \%$. Table 1 presents children's degree of disability, as rated by teachers with the ABILITIES Index (Simeonsson \& Bailey, 2005).

Participants included 86 regular ECE teachers (1 male), aged between 24 and 60 years $(M=46.45, S D=8.46)$. About $96 \%$ of these teachers had at least one year of experience in inclusive classrooms and $42 \%$ had experience in early childhood intervention or early childhood special education. Regarding type of center, $78 \%$ of participating classrooms were in public preschools, $15 \%$ were in private non-profit centers, and $7 \%$ were in private for-profit 
centers. About $84 \%$ of the classrooms were mixed-aged, $7 \%$ served four-year-olds, and $9 \%$ served five-year-olds. Group size ranged between 14 and 27 children $(M=21.30, S D=2.53)$.

\section{Measures}

Degree of disability. We obtained a composite score of children's degree of disability from the ABILITIES Index (Simeonsson \& Bailey, 2005). The ABILITIES Index assesses children's functional (dis)abilities in nine domains (19 items), namely, audition, behavior and social skills, intellectual functioning, limbs, intentional communication, tonicity, integrity of physical health, eyes, and structural status. Each item was rated on a 6-point scale $(1=$ normal ability, 2 = suspected difficulty, $3=$ mild difficulty, $4=$ moderate difficulty, $5=$ severe difficulty, and $6=$ profound difficulty) by the teacher. As proposed by the authors, we computed a weighted composite score for children's degree of disability across all domains, with the following intervals: normal ability, $29 \leq \Sigma<58$; suspected difficulty, $58 \leq \Sigma<87$; mild difficulty, $87 \leq \Sigma<116$; moderate difficulty, $116 \leq \Sigma<145$; severe difficulty, $145 \leq \Sigma<$ 174; and profound difficulty, $\Sigma=174$. This measure has shown good reliability and validity in studies using Portuguese samples (e.g., Grande \& Aguiar, 2011). In this study, internal consistency for the composite score was .81.

Verbal abilities. The Portuguese adaptation of the Wechsler Preschool and Primary Scale of Intelligence - Revised (WPPSI-R; Wechsler, 2010) was used to assess children's verbal cognitive abilities. We used the mean scores of four to five subtests of the verbal scale: information, arithmetic, vocabulary, similarities, and comprehension (optional). The optional test was used exceptionally, with children who did not understand or did not respond to the core tests. Scores were adjusted for age $(M=10, S D=3)$. Internal consistency was .92 .

Social skills and problem behaviors. The teachers' preschool version of the Social Skills Rating System (SSRS; Gresham \& Elliott, 2007) was used to assess children's social skills and problem behaviors. Similar to previous studies (e.g., Aguiar et al., 2010), two scales 
were used: social skills (30 items, $\alpha=.93$ ) and problem behaviors (10 items, $\alpha=.82$ ). Two subscales of problem behaviors were also obtained: externalizing behaviors ( 6 items, $\alpha=.85$ ) and internalizing behaviors ( 4 items, $\alpha=.68$ ). Teachers rated the frequency of children's behavior: $0=$ never, $1=$ sometimes, $2=$ very often .

Number of friends. We used sociometric peer nominations and ratings to identify the number of reciprocal friends of each child. Reciprocal friendships were identified when a child with disabilities both nominated and rated positively a peer and, in turn, the same peer nominated and rated positively the child with disabilities. This measure has been previously used to identify the friendships of young children with disabilities (Meyer \& Ostrosky, 2016; Yu, Ostrosky, \& Fowler, 2012). Previous research has shown that preschoolers can reliably report reciprocal friendships based on sociometric picture techniques (Howes, 2009).

Social acceptance. Individual children's social acceptance scores were obtained as the standardized score ( $z$ score) of the sum of all peer ratings in each classroom.

Classroom quality. The Classroom Assessment Scoring System (CLASS) (Pianta et al., 2008) is an observation measure designed to assess three domains of classroom quality: emotional support, classroom organization, and instructional support. Emotional support ( $\alpha=$ .90) comprises four dimensions: positive climate, negative climate, teacher sensitivity, and regard for student perspectives. Classroom organization $(\alpha=.86)$ includes behavior management, productivity, and instructional learning formats. Finally, instructional support ( $\alpha$ $=.87$ ) includes concept development, quality of feedback, and language modeling. CLASS dimensions are rated on a Likert 7-point scale (1-2 = low quality, 3-5 = middle quality, and 6$7=$ high quality). In this study, a mean score was computed for each CLASS domain and an overall score of classroom quality $(\alpha=.92)$ was computed as the mean of all 10 dimensions.

ECE dosage. Children's exposure to ECE was measured through teachers' report of days absent in the current school year and the total number of months with the lead teacher. 


\section{Procedure}

This study was part of a broader research project, Enhancing peer relationships: Preschool teachers' ideas and practices, authorized by the National Authority for Data Protection and by the Directorate-General of Education. It was based on the same dataset used by Ferreira, Aguiar, Correia, Fialho, \& Pimentel, 2017). Data were collected in 2012/2013 and 2013/2014. Each school year, we contacted, through e-mail, half of the public-school clusters (with telephone follow-ups, within two weeks) in the district of Lisbon as well as private (profit and nonprofit) centers identified as having inclusive classrooms by early childhood intervention teams. Next, we conducted telephone calls and/or meetings with ECE teachers willing to participate, to provide further information on study goals and methods. Next, parents were asked to provide written consent. ECE classrooms were eligible if (1) they included at least one child receiving special education or early childhood intervention services under Decree-Law No. 3/2008 or Decree-Law No. 281/2009, and (2) at least 60\% of all the children had parental consent to participate in sociometric interviews. Overall, we contacted 255 public school clusters and private ECE centers and recruited 40 centers.

One child with disabilities was randomly selected per classroom to avoid nesting effects. Children with multiple, severe disabilities were excluded because we anticipated they would emerge as extreme outliers and because examination of their social experiences requires tailored measures and procedures. All teachers and parents of participating children signed informed consent forms and children provided verbal assent.

Children's (dis)abilities, social skills, and problem behaviors were assessed using teachers' reports at least two months after the beginning of the school year. The WPPSI-R was applied individually in a quiet room at the ECE center by trained psychologists.

Friendship and social acceptance data were collected in a separate room at the ECE center at least four months after the beginning of the school year, to allow children's peer relationships 
to become stable. Individual sociometric interviews were conducted with all children in the classroom with parental consent and two different sociometric procedures were used: peer nominations and peer ratings. Using photographs of all children in each classroom, we first conducted the peer nomination task, asking children to make three positive nominations ("With whom do you like to play the most") and three negative nominations ("With whom do you like to play the least"). We then conducted the peer ratings task, asking children to sort the photos of their peers into one of three boxes. Children were asked to place the photos of peers they "liked to play with a lot" (rating of 3 ) inside a box with a happy face; to place the photos of peers they "liked to play with sometimes" (rating of 2) in a box with a neutral face; and, finally, the photos of peers they "did not like to play with" (rating of 1) in a box with a sad face. Children with disabilities were also invited to participate, except in two cases due to their disability profile (i.e., affecting vision or communication). Six children did not understand the sociometric tasks and one child left the center prior to sociometric data collection. Therefore, sociometric data for computing children's friendships and social acceptance were available for 77 children.

We conducted four observation cycles per classroom typically in the morning. Each cycle lasted about 30 minutes, with 20 minutes for observation and 10 minutes for scoring. For each dimension, the mean score across the four cycles was calculated. Four observers previously trained and certified for the Pre-K CLASS version conducted all observations. Reliability checks were performed in $27.9 \%$ of participating classrooms and ICCs ranged from .57 (instructional support) to .68 (emotional support). ICC for the overall CLASS score was .63. Mean interrater percent agreement within-1 point was $96.5 \%$ for emotional support, 92\% for classroom organization, $98.9 \%$ for instructional support, and $95.71 \%$ overall agreement across all dimensions. CLASS domains were highly correlated (Pearson $r$ between .54 and .77). 


\section{Results}

\section{Descriptive statistics}

Table 2 displays means, standard deviations, and correlation coefficients. Children presented low social acceptance and few reciprocal friendships (about 56\% of children had no friends). CLASS scores suggested middle-quality levels for emotional support $(M=5.01, S D$ $=0.81)$ and classroom organization $(M=4.92, S D=0.80)$, and low-quality levels for instructional support $(M=1.69, S D=0.48)$. About $7 \%$ of the children experienced low quality and $93 \%$ of the children experienced moderate levels of classroom quality $(M=3.99$, $S D=0.63$ ). To ensure parsimony, based on zero-order correlations, fathers' education, and internalizing behaviors were not included in subsequent analyses.

\section{Classroom quality and social acceptance and friendships: The moderating role of dosage}

Multiple regression analyses were conducted to test the associations between classroom quality and children's social acceptance and friendships, investigating the moderating role of dosage. Three models were tested for each outcome: Model 1 included mothers' education, children's age, degree of disability, verbal abilities, social skills, externalizing behavior, proportion of days absent, number of months with the teacher, and classroom quality; Model 2 added the moderating effects of the proportion of days absent; and Model 3 added the moderating effects of the number of months with the teacher. Listwise deletion was used, resulting in an analytical sample of $N=71$ for social acceptance and $N=67$ for friendships.

For social acceptance, Models 1 and 3 (Table 3) indicated a significant negative effect of externalizing behavior $\left(F(9,62)=2.24, p=.03, R^{2}{ }_{a}=.14\right.$ and $F(10,61)=2.16, p=.03, R^{2}{ }_{a}$ $=.14$, respectively). Model 2 was not statistically significant. Contrary to our hypotheses (H1.1, H1.1a, and H1.1b), classroom quality was not associated with the social acceptance of children with disabilities and we did not find evidence of moderating effects of ECE dosage. 
Regarding friendships (Table 4), Model 1 was statistically significant, $F(9,57)=2.24, p$ $=.03, R_{a}^{2}=.15$, but no effects were found for any of the predictors. Further, similar to social acceptance, the model testing the moderating effects of days absent was not statistically significant. Model 3 was statistically significant, $F(10,56)=2.12, p=.04, R^{2}{ }_{a}=.15$, but only a positive main effect of verbal abilities was found. Therefore, contrary to our expectations (H1.2, H1.2a, and H1.2b), classroom quality was not associated with the number of friends for children with disabilities. We also did not find moderating effects for ECE dosage.

\section{Children's skills and social acceptance and friendships: The moderating role of dosage}

Finally, multiple regression analyses were conducted to investigate the moderating effects of ECE dosage on the associations between children's verbal abilities, social skills, and externalizing behaviors and children's social acceptance and friendships. For this purpose, two additional models were tested for each social outcome: the first model tested the moderating effects of days absent; the second model tested the moderating effects of the number of months with the teacher (see Table 5). Both models included the same predictors previously tested. Model 1 revealed moderating effects of days absent in the associations between children's verbal abilities and children's externalizing behaviors and their social acceptance, $F(12,59)=4.33, p<.001, R^{2}{ }_{\mathrm{a}}=.36$. Further, in this model we also found positive effects for maternal education, degree of disability, and classroom quality. Figure 2 plots the moderating effect of days absent in the association between externalizing behavior and social acceptance. ModGraph-I (Jose, 2013) and Excel were used to plot these effects. Contrary to our hypothesis (H4.1a), children with lower levels of externalizing behavior seemed to benefit from missing fewer school days. Also, increased attendance (i.e., fewer days absent) was associated with lower peer social acceptance for children with higher levels of externalizing behavior. Figure 2 also plots the moderating effects of days absent in the association between verbal abilities and social acceptance. Contrary to $\mathrm{H} 2.1 \mathrm{a}$, children with lower verbal abilities 
had higher social acceptance when missing more school days and increased attendance was associated with higher social acceptance for children with higher verbal abilities.

Regarding friendship (Table 5), the two models tested were statistically significant: $F(12)=2.82,, p=.01, R_{a}^{2}=.25$ and $F(12,54)=2.13, p=.03, R_{a}^{2}=.17$, respectively. Model 2 revealed a positive main effect of children's verbal abilities and moderating effects of the number of months with the teacher in the association between externalizing effects and number of friends. As shown in Figure 3, contrary to H4.2b, children with lower levels of externalizing behavior had more friends when spending more months with the teacher (controlling for classroom quality). The inverse pattern was found for children with higher levels of externalizing behavior.

\section{Discussion}

We examined the associations between observed classroom quality and the friendships and peer social acceptance of young children with disabilities, while testing the moderating effects of ECE dosage. We also investigated the associations between children's verbal, social, and behavioral skills and their friendships and social acceptance, assuming these associations would also be moderated by ECE dosage. We addressed these issues in a European sample, thus adding to the evidence base outside the United States of America. Further, we relied on multiple methods and sources, including independent classroom observations, teacher reports, and children's sociometric nominations and ratings.

As in previous research, children with disabilities had few friends (Meyer \& Ostrosky, 2016) and relatively low levels of social acceptance (Aguiar et al., 2010; Odom et al., 2006). Classroom quality was not consistently associated with children's social acceptance and friendships and ECE dosage did not moderate this association. Therefore, our findings did not support our hypotheses and differed from previous studies relating ECE classroom quality with children's social development (Mashburn et al, 2008; Mikami et al., 2012). It is possible 
that the moderate quality observed in this sample is insufficient to influence children's social experiences at the dyadic and group level. Consistent with this hypothesis, Burchinal et al. (2010) found that low and moderate classroom quality did not improve outcomes for children at risk for delays. This suggests that children with disabilities require more intensive and individualized interventions to show gains in peer-related social outcomes (see Brown, Odom, \& Conroy, 2001). Importantly, recent research suggests children attending inclusive classrooms may experience lower quality, especially regarding language support and concept development (Cadima et al., 2018; Pelatti, Dynia, Logan, Justice, \& Kaderavek, 2016).

When examining the associations between children's individual skills and their friendships and social acceptance, we found externalizing behaviors were negatively associated with peer social acceptance. This finding is consistent with previous reports (e.g., Meyer \& Ostrosky, 2016) and was expected. Interestingly, externalizing behaviors were not associated with children's friendships, which supports the diverse nature of these constructs, with externalizing behaviors influencing group-level social outcomes but not dyadic relationships. For friendships, a positive main effect of verbal abilities was found in both models testing the moderating effects of the number of months with the teacher. This association is congruent with previous literature suggesting children with poor language skills experience peer relationship difficulties (Son et al., 2014). Contrary to what was expected and different from previous research (Meyer \& Ostrosky, 2016; Son et al., 2014), we did not find direct or moderated effects of social skills on children's social acceptance or friendships.

We further hypothesized ECE dosage would moderate the associations between children's verbal, social, and behavior skills and their friendships and social acceptance. Although we found evidence of moderating effects of ECE dosage on some of these associations, the direction of the effects diverged from our initial expectations. Children with lower verbal abilities and children with more externalizing behaviors seemed to have an 
increased risk of social rejection when they attended school more often. Further, children with increased levels of externalizing behavior had more friends when spending fewer months with the teacher while children with lower levels of externalizing behaviors had more friends when spending more months with the teacher. Collectively, our findings suggest that exposure to ECE matters, but in an unexpected way: simply increasing the attendance of children with disabilities or ensuring prolonged exposure to a teacher does not ensure positive group-level social outcomes or enhance dyadic peer relationships of children with more verbal and behavioral difficulties. For these children, more time with the peer group or with the teacher may be detrimental in establishing friendships and being accepted by peers, at least in the context of moderate-quality ECE. Children struggling with behavioral and language issues who spend more time in the classroom should; therefore, be specifically targeted for interventions aiming to promote group membership.

Successful inclusion requires teachers to support children's peer relationships intentionally and over time. Despite valuing this type of relationship teachers are more likely to use incidental strategies to support the friendships of children with disabilities (Hollingsworth \& Buysse, 2009). More passive strategies such as allowing children to choose peers for specific activities or providing free choice opportunities are preferred, likely because teachers believe they should not interfere in children's relationships (Hollingsworth \& Buysse, 2009). Importantly, Meyer and Ostrosky (2018) reported moderate levels of agreement between teachers and young children regarding the identification of children's friends, with decreased accuracy reported for children with disabilities. Relatedly, in a previous study with this dataset (Ferreira et al., 2017), we found teachers' reports on children's sociometric status were weakly associated with sociometric status based on peer sociometric nominations. Together, these findings may reflect teachers' limited awareness of peer-related experiences and social rejection processes experienced by children with 
disabilities, which may hinder teacher's efforts to support children's friendships and social acceptance over time.

\section{Limitations and Future Research}

This study has limitations that must be addressed. First, we acknowledge the small size and regional scope of our community-based ECE sample, resulting in limited statistical power and limits to the generalization of findings. The small sample and vast array of disabilities of participating children also prevented the conduction of analyses considering children's type of disabilities. Even though we controlled for the severity of children's disabilities, a closer examination of children's disability profile was not possible. Second, our cross-sectional correlational design does not allow us to establish causal effects or unequivocally establish the direction of the associations reported here. Third, although we considered two indicators of children's ECE dosage, we did not control for time children with disabilities spent outside their classrooms to receive pull-out services. Previous research has reported benefits for children served through in-class support models when compared with children experiencing pull-out services (Vlachou \& Fyssa, 2016). Son et al. (2014) also found negative effects of pull-out services for children with disabilities, reporting that children who spend more time in special education classrooms have poorer language and decreased social skills, which is likely to increase their peer-related difficulties. Therefore, future research should also account for time spent outside the classroom for pull-out services. We also did not measure reasons for children's absences from school; we do not know whether children were absent due to health issues or distress in the family (see Logan, Piasta, Justice, Schatschneider, \& Petrill, 2011). However, we do know children were not absent due to disciplinary actions. In the Portuguese system, suspension is not applicable to children attending ECE, changing schools due to behavioral issues is not allowed until children reach 10 years of age, and expulsion is not permitted before 18 years of age (Law No. 51/2012). Fourth, our study does not add to the 
understanding of the social experiences of children with the most severe disabilities, who were either excluded based on sample selection criteria or could not participate or understand the sociometric tasks. Fifth, although we used a conventional and well-established measure of children's friendships — one that captures the dyadic and reciprocal nature of children's relationships and has been used with young children with disabilities (Meyer \& Ostrosky, 2016; Yu et al., 2012) — we elicited children's perspectives on preferred playmates, assuming enjoyment of joint play was a property of children's friendships, but did not elicit children's reports of their (best) friends explicitly (Meyer \& Ostrosky, 2018).

Finally, our measurement of classroom quality describes the overall experiences of all children in the group and scores may not reflect the experiences of individual children with disabilities. We also did not focus specifically on how teachers facilitate target children's interactions and relationships with typically developing children nor does it measure peer interactions explicitly. Considering our goals, a more targeted approach, focusing on the quality of the dyadic interactions between teachers and individual children as well as peer interactions, may have been appropriate and more likely to detect hypothesized effects (Burchinal, 2010). Further, considering evidence suggesting that teacher-child interaction might hinder peer social interaction (Coplan \& Prakash, 2003; Harper \& McCluskey, 2003; Tsao et al., 2008), future research may benefit from measuring teacher's facilitation of peer relationships between children with and without disabilities. Because positive peer interactions are important for the development of social competence, friendships, and social acceptance (e.g., Meyer \& Ostrosky, 2016), future research should investigate peer interactions as a potential mediator between classroom quality and the friendships and social acceptance of children with disabilities.

\section{Conclusions and Implications}


Children with disabilities attending inclusive ECE settings in Lisbon, Portugal, experience medium classroom quality and struggle with dyadic and group-level dimensions of social inclusion. The lack of associations between classroom quality and social outcomes suggests the need to improve ECE quality and reach the high-quality levels likely needed to positively influence children's social development (Burchinal et al., 2010). The moderate quality observed signals the need to ensure that all children, and especially those in need of additional supports, benefit from ECE with individualized and intentional social skills instruction. To this effect, quality improvement systems must be designed and implemented.

Externalizing behavior and verbal abilities were related to children's peer-related social experiences, but these associations were moderated by ECE dosage. The somewhat counterintuitive effects of dosage reported here (i.e., more time in ECE associated with lower social acceptance for children with higher externalizing behaviors and lower verbal abilities) suggest that simply spending more time in ECE settings is not sufficient for positive social outcomes to emerge and that, over time, children with more externalizing behaviors and lower verbal abilities, may need additional - more intensive and individualized - supports to develop and maintain friendships and be accepted in the peer group.

These findings are consistent with the Policy Statement on Inclusion of Children with Disabilities in Early Childhood Programs (U.S. Health and Human Services \& U.S. Department of Education, 2016), which highlighted the importance of teachers' knowledge regarding strategies to support children's socio-emotional development, decrease challenging behavior, and engage children in high-quality interactions. Our findings suggest that addressing children's socio-emotional development and behavioral health in teacher training also is important to overcome barriers to social inclusion in Portuguese ECE settings. Specifically, evidence-based multi-tiered systems of support focusing on increasing social emotional competence and decreasing challenging behavior, such as the Pyramid Model for 
Supporting Social Emotional Competence in Infants and Young Children (Hemmeter, Snyder, Fox, \& Algina, 2016), may be particularly helpful. Such models (Brown et al., 2001) may support Portuguese ECE teachers, families, and specialists in engaging in a sequential and purposeful decision-making process, aiming to support the friendships and peer group social acceptance of preschoolers with disabilities: from classroom wide or universal interventions built on positive relationships and supportive environments, to targeted social emotional supports and, eventually, intensive individualized interventions, as needed. 


\section{References}

Aguiar, C., Moiteiro, A. R., \& Pimentel, J. S. (2010). Classroom quality and social acceptance of preschoolers with disabilities. Infants \&Young Children, 23, 34-41. doi:10.1097/IYC.0b013e3181c9766e

Bronfenbrenner U., \& Morris P. A. (2006). The bioecological model of human development. In W. Damon (Series Ed.) \& R. M. Lerner (Vol. Ed.), Handbook of child psychology: Theoretical model of human development (pp. 793-828). New York, NY: John Wiley.

Brown, W.H., Odom, S. L., \& Conroy, M. A. (2001). An intervention hierarchy for promoting young children's peer interactions in natural environments. Topics in Early Childhood Special Education, 21, 162-175. doi:10.1177/027112140102100304

Burchinal, M. (2010). Differentiating among measures of quality: Key characteristics and their coverage in existing measures. OPRE Research-to-Policy, Research-to-Practice Brief OPRE 2011-10b, Washington, DC: Office of Planning, Research and Evaluation, Administration for Children and Families, U.S. Department of Health and Human Services.

Burchinal, M., Howes, C., Pianta, R., Bryant, D., Early, D., Clifford, R., \& Barbarin, O. (2008). Predicting child outcomes at the end of kindergarten from the quality of prekindergarten teacher-child interactions and instruction. Applied Developmental Science, 12, 140-153. doi:10.1080/10888690802199418

Burchinal, M., Vandergrift, N., Pianta, R., \& Mashburn, A. (2010). Threshold analysis of association between child care quality and child outcomes for low-income children in pre-kindergarten programs. Early Childhood Research Quarterly, 25, 166-176. doi:10.1016/j.ecresq.2009.10.004

Buyse, E., Verschueren, K., Doumen, S., Damme, J. Van, \& Maes, F. (2008). Classroom problem behavior and teacher-child relationships in kindergarten: The moderating role 
of classroom climate. Journal of School Psychology, 46, 367-391.

doi:10.1016/j.jsp.2007.06.009

Buysse, V., Goldman, B. D., \& Skinner, M. L. (2002). Setting effects on friendship formation among young children with and without disabilities. Exceptional Children, 68, 503517. doi:10.1177/001440290206800406

Cadima, J., Aguiar, C., \& Barata, M. C. (2018). Process quality in Portuguese preschool classrooms serving children at-risk of poverty and social exclusion and children with disabilities. Early Childhood Research Quarterly, 45, 93-105.

doi:10.1016/j.ecresq.2018.06.007

Coplan, R. J., \& Prakash, K. (2003). Spending time with teacher: Characteristics of preschoolers who frequently elicit versus initiate interactions with teachers. Early Childhood Research Quarterly, 18, 143-158. doi:10.1016/S0885-2006(03)00009-7

Cryer, D., Tietze,W., Burchinal, M., Leal, T., \& Palacios, J. (1999). Predicting process quality from structural quality in preschool programs: A cross country comparison. Early Childhood Research Quarterly, 14, 339-361. doi:10.1016/S0885-2006(99)00017-4

DEC/NAEYC. (2009). Early childhood inclusion: A joint position statement of the Division for Early Childhood (DEC) and the National Association for the Education of Young Children (NAEYC). Chapel Hill: The University of North Carolina, FPG Child Development Institute.

Decree-Law No. 3/2008. Ministério da Educação. Diário da República - $1^{\text {a }}$ Série n. ${ }^{\circ} 4-7$ de Janeiro de 2008, pp. 154-164.

Decree-Law No. 281/2009. Diário da República - $1^{\text {a }}$ Série n. ${ }^{o} 193$ - 6 de Outubro de 2009, pp. 7298-7301.

Decree-Law No. 65/2015. Ministério da Educação. Diário da República, $1^{\text {a }}$ série n. ${ }^{\circ} 128$ - 3 de Julho de 2015, p. 4572. 
DGEEC. (2015). Educação em números: Portugal 2015 [Education in numbers - Portugal 2015]. Retrieved from http://www.dgeec.mec.pt/np4/96/\%7B \$clientServletPath\%7D/?newsId=145\&fileName =Educac_a_o_em_nu_meros_2015.pdf.

DGEEC. (2016). Questionário das Necessidades Especiais de Educação: Ano letivo 2015/2016 [Special education needs: School year 2015/2016]. Retrieved from http://www.dgeec.mec.pt/np4/224/\%7B \$clientServletPath\%7D/?newsId=334\&fileNam e=DGEEC_DSEE_DEEBS_2016_NEE2.pdf

Diamond, K., Hong, S.-Y., \& Tu, H. (2008). Context influences preschool children's decisions to include a peer with a physical disability in play. Exceptionality, 16, 141155. doi:10.1080/09362830802198328

Downer, J., Sabol, T. J., \& Hamre, B. (2010). Teacher-child interactions in the classroom: Toward a theory of within- and cross domain links to children's development outcomes. Early Education and Development, 21, 699-723. doi:10.1080/10409289.2010.497453

Ferreira, M., Aguiar, C., Correia, N., Fialho, M., \& Pimentel, J. S. (2017). Social experiences of children with disabilities in Portuguese inclusive preschool settings. Journal of Early Intervention, 39(1), 33-50. doi: 10.1177/1053815116679414

Gamelas, A. M. (2003). Contributos para o estudo da qualidade de contextos pré-escolares inclusivos [Contributes to the study of quality in inclusive preschool settings]. Psicologia, XVII, 195-226. doi:10.17575/rpsicol.v17i1.445

Goldman, B. D. (2007). What early educators and parents can do to support friendships in early childhood. Children and Families, Spring/ Summer, 12-15. Retrieved from http://www.nectac.org/ pdfs/Meetings/InclusionMtg2007/Goldman_HeadStartcolorfina 1II.pdf 
Grande, C., \& Aguiar, C. (2011). O Índice de capacidades: dois estudos. In A. S. Ferreira (Ed.), Actas do VIII Congresso Iberoamericano de Avaliação/Evaluación Psicológica. XV Conferência Internacional Avaliação Psicológica: Formas e Contextos (pp. 11461160). Lisboa: Sociedade Portuguesa de Psicologia.

Gresham, F., \& Elliott, S. (2007). Social Skills Rating System (C. Aguiar, Trans.). Lisboa: Unidade de Investigação em Psicologia Cognitiva, do Desenvolvimento e da Educação, ISPA - Instituto Universitário. (Original work published in 1990).

Harper, L. V., \& McCluskey, K. S. (2003). Teacher-child and child-child interactions in inclusive preschool settings: Do adults inhibit peer interactions? Early Childhood Research Quarterly, 18, 163-184. doi:10.1016/S0885-2006(03)00025-5

Hemmeter, M. L., Snyder, P. A., Fox, L., \& Algina, J. (2016). Evaluating the implementation of the Pyramid Model for promoting social-emotional competence in early childhood classrooms. Topics in Early Childhood Special Education, 36, 133-146. doi:10.1177/0271121416653386

Hollingsworth, H. L., \& Buysse, V. (2009). Establishing friendships in early childhood inclusive settings: What roles do parents and teachers play? Journal of Early Intervention, 31, 287-307. doi:10.1177/1053815109352659

Howes, C. (2009). Friendship in early childhood. In K. H. Rubin, W. M. Bukowski, \& B. Laursen (Eds.), Handbook of peer interactions, relationships, and groups (pp. 180-194). New York, NY: The Guilford Press.

Inspeção-Geral de Educação e Ciência. (2015). Organização do Ano Letivo 2014-2015: Relatório [Organization of the 2014/2015 school year: Report]. Retrieved from http://www.ige.min-edu.pt/upload/Relatorios/OAL_2014-2015_Relatorio.pdf Johnson, S. R., Seidenfeld, A. M., Izard, C. M., \& Kobak, R. (2013). Can classroom emotional support enhance prosocial development among children with depressed 
caregivers? Early Childhood Research Quarterly, 28, 282-290.

doi:10.1016/j.ecresq.2012.07.003

Jose, P. E. (2013). ModGraph-I: A programme to compute cell means for the graphical display of moderational analyses: The internet version, Version 3.0. Victoria University of Wellington, New Zealand. Retrieved from http://pavlov.psyc.vuw.ac.nz/pauljose/modgraph/

Law No. 51/2012. Assembleia da República. Diário da República, 1. ${ }^{a}$ série — N. ${ }^{\circ} 172-5$ de setembro de 2012, pp. 5103-5119.

Logan, J. A., Piasta, S. B., Justice, L. M., Schatschneider, C., \& Petrill, S. (2011). Children's attendance rates and quality of teacher-child interactions in at-risk preschool classrooms: Contribution to children's expressive language growth. Child \& Youth Care Forum, 40, 457-477. doi:10.1007/s10566-011-9142-x

Mashburn, A. J., Pianta, R. C., Hamre, B. K., Downer, J. T., Barbarin, O. A., Bryant, D., . . . Howes, C. (2008). Measures of classroom quality in prekindergarten and children's development of academic, language, and social skills. Child Development, 79, 732-749. doi:10.1111/j.1467-8624.2008.01154.x

Meyer, L. E., \& Ostrosky, M. M. (2016). Impact of an affective intervention on friendship of kindergarteners with disabilities. Topics in Early Childhood Special Education, 35, 200210. doi:10.1177/0271121415571419

Meyer, L. E., \& Ostrosky, M. M. (2018). Identifying classroom friendships: Teachers' confidence and agreement with children. Topics in Early Childhood Special Education, 38, 94-104. doi:10.1177/0271121418763543

Mikami, A. Y., Griggs, M. S., Reuland, M. M., \& Gregory, A. (2012). Teacher practices as predictors of children's classroom social preference. Journal of School Psychology, 50, 95-111. doi:10.1016/j.jsp.2011.08.002 
Odom, S. L., Zercher, C., Li, S., Marquart, J. M., Sandall, S., \& Brown, W. H. (2006). Social acceptance and rejection of preschool children with disabilities: A mixed-method analysis. Journal of Educational Psychology, 98, 807-823. doi:10.1037/00220663.98.4.807

Pelatti, C. Y., Dynia, J. M., Logan, J. A. R., Justice, L. M., \& Kaderavek, J. (2016). Examining quality in two preschool settings: Publicly funded early childhood education and inclusive early childhood education classrooms. Child Youth Care Forum, 45, 829-849. doi:10.1007/s10566-016-9359-9

Pianta, R. C., LaParo, K. M., \& Hamre, B. K. (2008). Classroom Assessment Scoring System Manual: Pre- K. Baltimore, MD: Brookes.

Reszka, S. S., Odom, S. L., \& Hume, K. A. (2012). Ecological features of preschools and the social engagement of children with autism. Journal of Early Intervention, 34, 40-56. doi:10.1177/1053815112452596

Rimm-Kaufman, S. E., Curby, T. W., Grimm, K. J., Nathanson, L., \& Brock, L. L. (2009). The contribution of children's self-regulation and classroom quality to children's adaptive behaviors in the kindergarten classroom. Developmental Psychology, 45, 958972. doi:10.1037/a0015861

Simeonsson, R. J., \& Bailey, D. B. (2005). Índice de Capacidades (C. Grande \& J. Bairrão, Trans.). Centro de Psicologia da Universidade do Porto. (Original work published 1991).

Son, E., Peterson, N. A., Pottick, K. J., Zippay, A., Parish, S. L., \& Lohrmann, S. (2014). Victimization among young children with disabilities: Early risk and protective factors. Exceptional Children, 80, 370-386. doi:10.1177/0014402914522422

Tsao, L.-L., Odom, S. L., Buysse, V., Skinner, M., West, T., \& Vitztum-Komanecki, J. (2008). Social participation of children with disabilities in inclusive preschool 
programs: Program typology and ecological features. Exceptionality: A Special Education Journal, 16, 125-140. doi:10.1080/09362830802198203

U.S. Department of Health and Human Services \& U.S. Department of Education. (2016). Policy statement on inclusion of children with disabilities in early childhood programs. Infants \&Young Children, 29, 3-24. doi:10.1097/IYC.0000000000000054

Vlachou, A., \& Fyssa, A. (2016). 'Inclusion in Practice': Programme practices in mainstream preschool classrooms and associations with context and teacher characteristics. International Journal of Disability, Development and Education, 63, 529-544. doi:10.1080/1034912X.2016.1145629

Wechsler, D. (2010). Escala de inteligência de Wechsler para a idade pré-escolar e primária: Forma revista. Lisboa: Cegoc.

West, T. (2008). Friendships of preschool children with disabilities: The role of child, adult, and program characteristics (Doctoral dissertation). Retrieved from https://cdr.lib.unc.edu/concern/parent/9z903116s/file_sets/gm80hw72r

Yu, S. Y., Ostrosky, M. M., \& Fowler, S. A. (2012). Measuring young children's attitudes toward peers with disabilities: Highlights from the research. Topics in Early Childhood Special Education, 32, 132-142. doi:10.1177/0271121412453175

Yu, S. Y., Ostrosky, M. M., \& Fowler, S. A. (2014). The relationship between preschoolers' attitudes and play behaviors toward classmates with disabilities. Topics in Early Childhood Special Education, 35, 40-51. doi:10.1177/0271121414554432

Xue, Y., Burchinal, M., Auger, A., Tien, H.-C., Mashburn, A., Peisner-Feinberg, E., . . . Tarullo, L. (2016). IV. Testing for dosage-outcome associations in early care and education. Monographs of the Society for Research in Child Development, 81(2), 6474. doi:10.1111/mono.12239 
Zaslow, M., Anderson, R., Redd, Z., Wessel, J., Tarullo, L., \& Burchinal, M. (2010). Quality dosage, thresholds, and features in early childhood settings: A review of the literature, OPRE 2011-5. Washington, DC: Office of Planning, Research and Evaluation, Administration for Children and Families, U.S. Department of Health and Human Services. 
Table 1

Participants' Level of Difficulty per Domain as Rated by Teachers on the ABILITIES Index (cells include number of children; $n=86$ )

\begin{tabular}{|c|c|c|c|c|c|c|c|c|c|c|}
\hline & Audition & Vision & Limbs & Tonicity & $\begin{array}{l}\text { Overall } \\
\text { health }\end{array}$ & $\begin{array}{c}\text { Structural } \\
\text { status }\end{array}$ & Behavior & $\begin{array}{l}\text { Social } \\
\text { Skills }\end{array}$ & Communication & $\begin{array}{l}\text { Intellectual } \\
\text { functioning }\end{array}$ \\
\hline Normal ability & 70 & 64 & 61 & 56 & 57 & 64 & 18 & 22 & 16 & 17 \\
\hline Suspected difficulty & 7 & 5 & 5 & 10 & 6 & 7 & 4 & 1 & 16 & 6 \\
\hline Mild difficulty & 4 & 5 & 14 & 11 & 8 & 2 & 20 & 22 & 21 & 11 \\
\hline Moderate difficulty & 2 & 9 & 4 & 4 & 10 & 10 & 29 & 30 & 25 & 27 \\
\hline Severe difficulty & 1 & 0 & 0 & 3 & 2 & 1 & 11 & 9 & 6 & 19 \\
\hline Profound difficulty & 0 & 1 & 0 & 0 & 1 & 0 & 1 & 0 & 0 & 4 \\
\hline
\end{tabular}

Note. Some columns do not add to 86 children due to missing data. 
Table 2

Descriptive Statistics and Pearson Correlation Coefficients Among Variables

\begin{tabular}{|c|c|c|c|c|c|c|c|c|c|c|c|c|c|c|c|}
\hline & 1 & 2 & 3 & 4 & 5 & 6 & 7 & 8 & 9 & 10 & 11 & 12 & 13 & 14 & 15 \\
\hline \multicolumn{16}{|l|}{ 1. Gender (1 = boys) } \\
\hline 2. Chronological age & -.05 & & & & & & & & & & & & & & \\
\hline 3. Mother's education & -.07 & -.21 & & & & & & & & & & & & & \\
\hline 4. Father's education & -.02 & -.04 & $.72^{* *}$ & & & & & & & & & & & & \\
\hline 5. Months with teacher & -.10 & $.23^{*}$ & .07 & .22 & & & & & & & & & & & \\
\hline 6. Proportion days absent & $-.24^{*}$ & -.05 & -.07 & .02 & -.06 & & & & & & & & & & \\
\hline 7. Degree of disability & -.09 & .07 & -.04 & .17 & -.02 & $.33^{* *}$ & & & & & & & & & \\
\hline 8. Verbal abilities & .02 & -.16 & $.36^{* *}$ & $.30^{*}$ & .18 & $-.28^{*}$ & $-.34^{* *}$ & & & & & & & & \\
\hline 9. Social skills & -.19 & .20 & -.05 & .00 & .08 & -.07 & -.17 & $.36^{* *}$ & & & & & & & \\
\hline 10. Problem behaviors & $.29^{* *}$ & -.06 & -.07 & -.03 & -.07 & -.08 & .18 & .12 & $-.52^{* *}$ & & & & & & \\
\hline 11. Externalizing & $.22^{*}$ & -.08 & -.06 & -.07 & -.04 & -.12 & .13 & .15 & $-.43^{* *}$ & $.92^{* *}$ & & & & & \\
\hline 12. Internalizing & $.28^{*}$ & .00 & -.05 & .06 & -.08 & .04 & .19 & -.01 & $-.44^{* *}$ & $.67^{* * *}$ & $.33^{* *}$ & & & & \\
\hline 13. Friendships & .19 & -.10 & .18 & .04 & .07 & $-.25^{*}$ & $-.28^{*}$ & $.46^{* *}$ & $.28^{*}$ & -.19 & -.19 & -.10 & & & \\
\hline 14. Social acceptance $z$ & -.14 & -.20 & $.24^{*}$ & .15 & -.05 & .10 & .12 & .01 & .04 & $-.30^{* *}$ & $-.31^{* *}$ & -.14 & $.34^{* *}$ & & \\
\hline 15. Classroom quality & .00 & -.09 & .06 & .02 & -.14 & -.05 & $.23^{*}$ & -.12 & .03 & -.06 & -.03 & -.08 & -.11 & .17 & \\
\hline$M$ & & 67.53 & 6.23 & 6.16 & 15.89 & 0.07 & 57.54 & 5.95 & 0.95 & 0.76 & 0.97 & 0.45 & 0.45 & -0.55 & 3.99 \\
\hline$S D$ & & 10.54 & 3.24 & 2.97 & 11.50 & 0.06 & 16.94 & 3.23 & 0.39 & 0.40 & 0.53 & 0.42 & 0.64 & 1.00 & 0.63 \\
\hline$N$ & & 86 & 78 & 69 & 84 & 84 & 83 & 81 & 86 & 86 & 86 & 86 & 76 & 84 & 85 \\
\hline
\end{tabular}

Note. Degree of disability ranges between 29 and 174. Scores on verbal abilities were adjusted for age (range $=1-19, M=10, S D=3$ ). Parent's education was measured as an ordinal variable with 12 levels, with level 6 corresponding to about 9 years of formal education. *p $<.05$. ** $p<$ .01 . 


\section{Table 3}

Summary of Multiple Regression Analyses for Testing the Moderating Effects of Dosage on the Association between Classroom Quality and Social Acceptance of Children with Disabilities $(N=71)$

\begin{tabular}{|c|c|c|c|c|c|c|c|c|c|}
\hline & \multicolumn{3}{|c|}{ Model 1} & \multicolumn{3}{|c|}{ Model 2} & \multicolumn{3}{|c|}{ Model 3} \\
\hline & $B$ & $S E$ & $\beta$ & $B$ & $S E$ & $\beta$ & $B$ & $S E$ & $\beta$ \\
\hline Chronological age & -0.02 & 0.01 & -.15 & -0.02 & 0.01 & -.15 & -0.02 & 0.01 & -.16 \\
\hline Mother's education & 0.07 & 0.04 & .24 & 0.07 & 0.04 & .24 & 0.07 & 0.04 & .23 \\
\hline Degree of disability & 0.00 & 0.01 & .08 & 0.00 & 0.01 & .08 & 0.00 & 0.01 & .08 \\
\hline Verbal abilities & -0.03 & 0.05 & -.10 & -0.03 & 0.05 & -.10 & -0.03 & 0.05 & -.10 \\
\hline Social skills & 0.33 & 0.38 & .12 & 0.33 & 0.38 & .12 & 0.23 & 0.39 & .09 \\
\hline Externalizing behaviors & -0.56 & 0.24 & $-.31 *$ & -0.56 & 0.24 & $-.31 *$ & -0.67 & 0.25 & $-.37 *$ \\
\hline Months with teacher & 0.00 & 0.01 & -.01 & 0.25 & 2.18 & .01 & 0.37 & 2.15 & .02 \\
\hline Days absent & 0.26 & 2.15 & .02 & 0.00 & 0.01 & -.01 & 0.00 & 0.01 & -.03 \\
\hline Classroom quality & 0.27 & 0.19 & .17 & 0.27 & 0.19 & .17 & 0.23 & 0.19 & .14 \\
\hline Classroom quality $*$ Days absent & & & & 0.12 & 3.18 & .00 & & & \\
\hline Classroom quality $*$ Months with teacher & & & & & & & 0.02 & 0.02 & .15 \\
\hline$R^{2}$ & & 25 & & & 25 & & & & \\
\hline$F$ for chance in $R^{2}$ & & $.24 *$ & & & .98 & & & $6 *$ & \\
\hline
\end{tabular}

Note. Predictors were mean-centered. $* p<.05 . * * p<.01$. 
Table 4

Summary of Multiple Regression Analyses Testing the Moderating Effects of Dosage on the Association between Classroom Quality and

Friendships of Children with Disabilities $(N=67)$

\begin{tabular}{|c|c|c|c|c|c|c|c|c|c|}
\hline & \multicolumn{3}{|c|}{ Model 1} & \multicolumn{3}{|c|}{ Model 2} & \multicolumn{3}{|c|}{ Model 3} \\
\hline & $B$ & $S E$ & $\beta$ & $B$ & $S E$ & $\beta$ & $B$ & $S E$ & $\beta$ \\
\hline Chronological age & 0.00 & 0.01 & .00 & 0.00 & 0.01 & .00 & 0.00 & 0.01 & .01 \\
\hline Mothers' education & 0.01 & 0.03 & .04 & 0.01 & 0.03 & .03 & 0.01 & 0.03 & .03 \\
\hline Degree of disability & 0.00 & 0.01 & -.10 & 0.00 & 0.01 & -.10 & 0.00 & 0.01 & -.09 \\
\hline Verbal abilities & 0.06 & 0.03 & .31 & 0.06 & 0.03 & .31 & 0.07 & 0.03 & $.33 *$ \\
\hline Social skills & 0.23 & 0.26 & .12 & 0.23 & 0.27 & .12 & 0.28 & 0.27 & .15 \\
\hline Externalizing behaviors & -0.06 & 0.16 & -.05 & -0.06 & 0.16 & -.05 & 0.00 & 0.17 & .00 \\
\hline Months with teacher & 0.00 & 0.01 & .01 & 0.00 & 0.01 & .02 & 0.00 & 0.01 & .03 \\
\hline Days absent & -1.39 & 1.62 & -.12 & -1.42 & 1.64 & -.12 & -1.52 & 1.62 & -.13 \\
\hline Classroom quality & -0.12 & 0.13 & -.12 & -0.12 & 0.13 & -.12 & -0.10 & 0.13 & -.09 \\
\hline Classroom quality $*$ Days absent & & & & 0.35 & 2.27 & .02 & & & \\
\hline Classroom quality $*$ Months with teacher & & & & & & & -0.01 & 0.01 & -.13 \\
\hline$R^{2}$ & & .26 & & & 26 & & & .28 & \\
\hline$F$ for Change in $R^{2}$ & & $2.24 *$ & & & 1.99 & & & $2.12 *$ & \\
\hline
\end{tabular}

Note. Predictors were mean-centered. $* p<.05 . * * p<.01$. 
Table 5

Summary of Multiple Regression Analyses Testing the Moderating Effects of Dosage on the Association between Children's Verbal, Social, and

Behavioral Skills and Children's Social Acceptance $(N=71)$ and Friendships $(N=67)$

\begin{tabular}{|c|c|c|c|c|c|c|c|c|c|c|c|c|}
\hline & \multicolumn{6}{|c|}{ Social acceptance } & \multicolumn{6}{|c|}{ Friendships } \\
\hline & \multicolumn{3}{|c|}{ Model 1} & \multicolumn{3}{|c|}{ Model 2} & \multicolumn{3}{|c|}{ Model 1} & \multicolumn{3}{|c|}{ Model 2} \\
\hline & $B$ & $S E$ & $\beta$ & $B$ & $S E$ & $\beta$ & $B$ & $S E$ & $\beta$ & $B$ & $S E$ & $\beta$ \\
\hline Chronological age & -0.01 & 0.01 & -.14 & -0.02 & 0.01 & -.15 & 0.00 & 0.01 & -.03 & 0.00 & 0.01 & -.03 \\
\hline Mothers' education & 0.09 & 0.03 & $.28 *$ & 0.06 & 0.04 & .21 & 0.03 & 0.03 & .13 & 0.00 & 0.03 & -.02 \\
\hline Degree of disability & 0.02 & 0.01 & $.26^{*}$ & 0.01 & 0.01 & .09 & 0.00 & 0.01 & -.03 & 0.00 & 0.01 & -.07 \\
\hline Verbal abilities & -0.05 & 0.04 & -.18 & -0.04 & 0.05 & -.13 & 0.05 & 0.03 & .22 & 0.07 & 0.03 & $.33^{*}$ \\
\hline Social skills & 0.60 & 0.33 & .22 & 0.49 & 0.41 & .18 & 0.38 & 0.25 & .21 & 0.33 & 0.28 & .18 \\
\hline Externalizing behaviors & -0.42 & 0.22 & -.23 & -0.54 & 0.24 & $-.30^{*}$ & -0.01 & 0.16 & -.01 & -0.09 & 0.16 & -.08 \\
\hline Months with teacher & 0.00 & 0.01 & -.05 & 0.00 & 0.01 & -.03 & 0.00 & 0.01 & .02 & 0.00 & 0.01 & -.03 \\
\hline Days absent & -1.82 & 1.94 & -.11 & 0.12 & 2.21 & .01 & -1.06 & 1.54 & -.09 & -1.07 & 1.60 & -.09 \\
\hline Classroom quality & 0.33 & 0.16 & $.21 *$ & 0.25 & 0.20 & .16 & -0.13 & 0.12 & -.12 & -0.04 & 0.14 & -.03 \\
\hline Verbal abilities * Days absent & -2.78 & 0.82 & $-.44 *$ & & & & -0.09 & 0.64 & -.02 & & & \\
\hline Social skills * Days absent & 9.69 & 6.53 & .21 & & & & -9.40 & 5.10 & -.28 & & & \\
\hline Externalizing $*$ Days absent & 17.55 & 5.66 & $.43^{*}$ & & & & 4.13 & 4.49 & .14 & & & \\
\hline Verbal abilities * Months w/ teacher & & & & 0.01 & 0.00 & .20 & & & & 0.00 & 0.00 & .03 \\
\hline Social skills $*$ Months w/ teacher & & & & -0.10 & 0.61 & -.02 & & & & 0.14 & 0.46 & .04 \\
\hline Externalizing $*$ Months $\mathrm{w} /$ teacher & & & & -0.01 & 0.02 & -.07 & & & & -0.03 & 0.01 & $-.28 *$ \\
\hline$R^{2}$ & .47 & & & .29 & & & .39 & & & .32 & & \\
\hline$F$ for Change in $R^{2}$ & $4.33 * *$ & & & $1.99 *$ & & & $2.82 *$ & & & $2.13^{*}$ & & \\
\hline
\end{tabular}

Note. Predictors were mean-centered. $* p<.05 . * * p<.01$. 
Dosage as moderator

a. Absences

b. Months with teacher

\begin{tabular}{|l|c|}
\multicolumn{1}{|c}{ Preditors } \\
1. Classroom quality \\
2. Verbal abilities \\
3. Social Skills \\
4. Problem behaviors \\
\hline
\end{tabular}

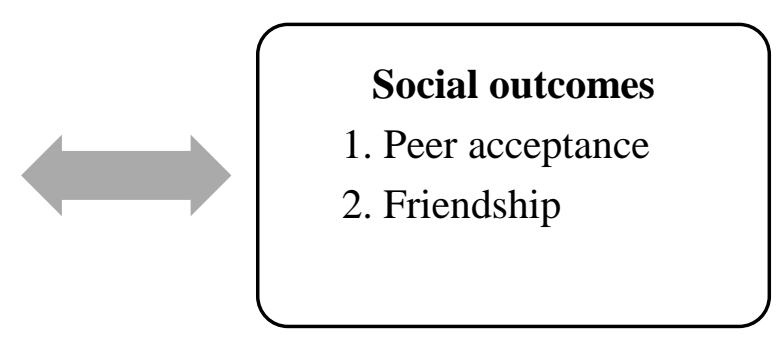

Figure 1. Simplified model of hypothesized associations among variables. 

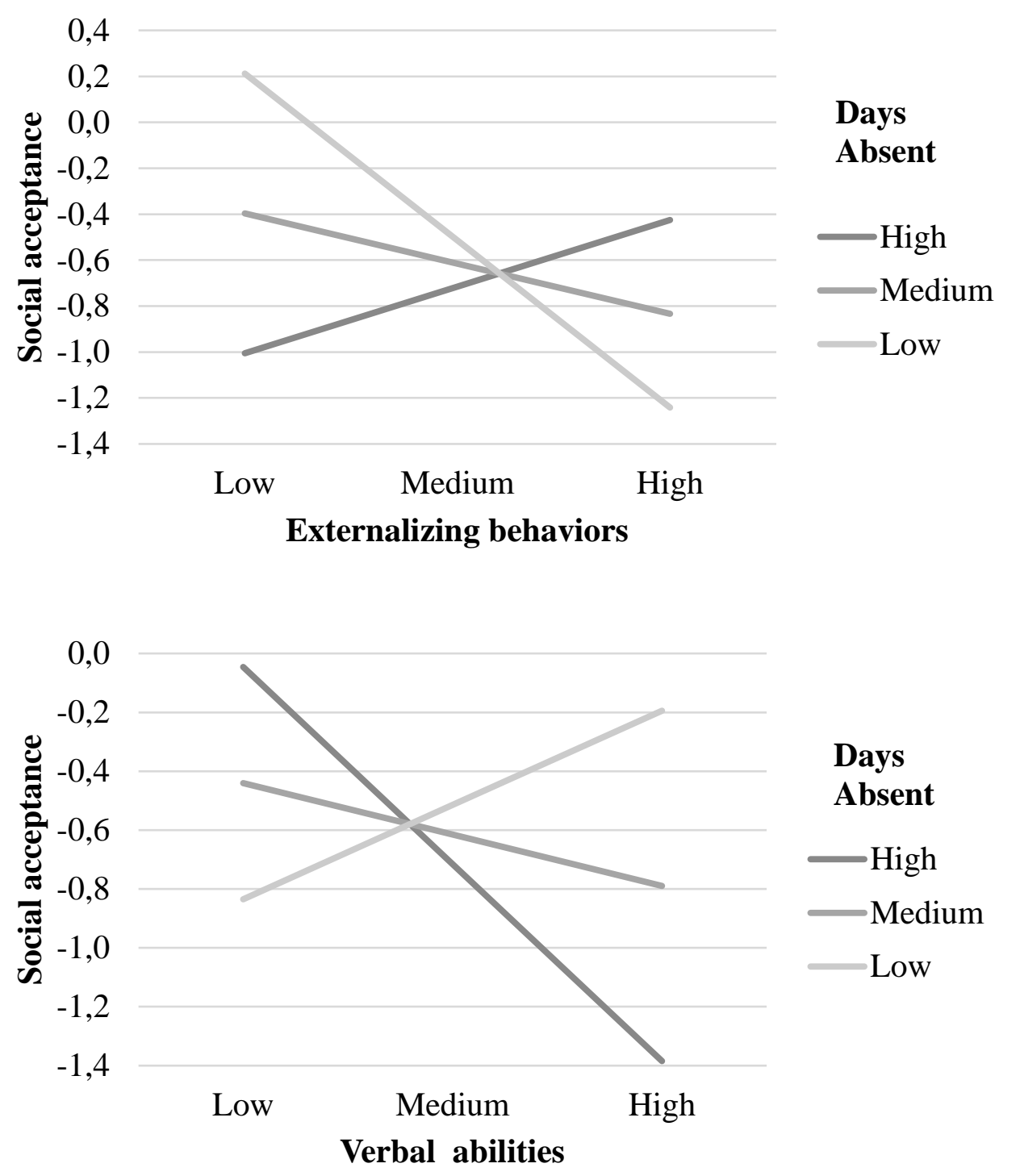

Figure 2. Moderating effects of proportion of days absent in the association between children's individual skills and social acceptance. 


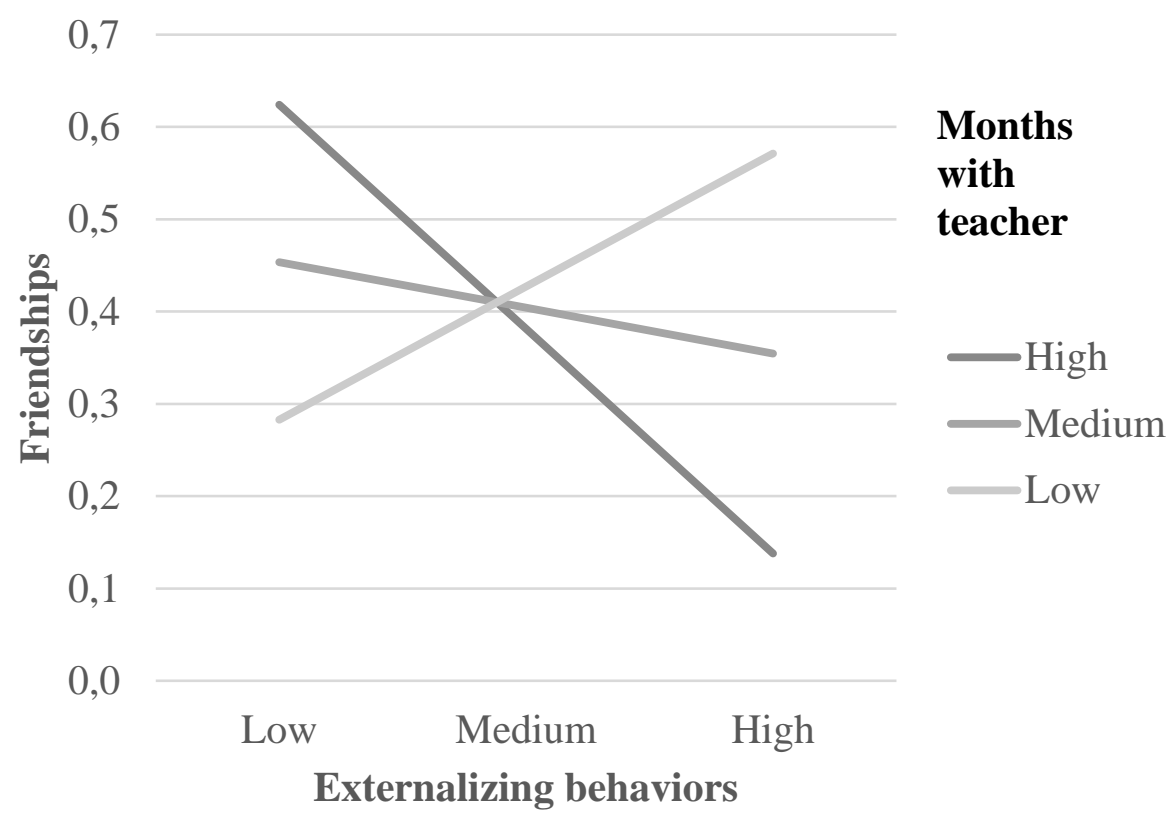

Figure 3. Moderating effects of number of months with the teacher in the association between externalizing behavior and number of reciprocal friends. 